\title{
PENGARUH IKLIM ORGANISASI TERHADAP KOMITMEN ORGANISASIONAL DAN RETENSI PEGAWAI KONTRAK DI BAPPEDA LITBANG PROVINSI BALI
}

\author{
Meliana Kurniawati Cahyadi ${ }^{1}$ \\ I Wayan Mudiartha Utama ${ }^{2}$ \\ ${ }^{1,2}$ Fakultas Ekonomi dan Bisnis Universitas Udayana, Bali, Indonesia \\ Email: meliana.cahyadi@gmail.com
}

\begin{abstract}
ABSTRAK
Retensi adalah elemen penting dari pendekatan organisasi. Setiap organisasi hendaknya berupaya mempertahankan karyawannya terutama karyawan yang memiliki nilai penting bagi organisasi. Mempertahankan bakat profesional terbaik adalah praktek sangat penting bagi organisasi seperti mengeliminasi rekrutmen, seleksi dan mengurangi biaya dari pergantian mereka, dan menjaga kontinuitas sesuai bidang keahlian mereka. Penelitian ini bertujuan untuk mengetahui pengaruh iklim organisasi terhadap komitmen organisasional dan retensi pegawai kontrak di Bappeda Litbang Provinsi Bali dengan menggunakan 66 orang sebagai responden penelitian. Teknik penentuan sampel yang digunakan dalam penelitian ini adalah menggunakan teknik sensus. Pengumpulan data dilakukan melalui wawancara dan kuesioner. Teknik analisis data yang digunakan pada penelitian ini adalah path analysis yang diolah menggunakan software SPSS. Hasil yang diperoleh dalam penelitian ini menunjukkan bahwa iklim organisasi memiliki hubungan yang positif dan signifikan terhadap komitmen organisasi, iklim organisasi memiliki hubungan yang positif dan signifikan terhadap retensi dan iklim organisasi memiliki hubungan yang positif dan signifikan terhadap retensi.

Kata kunci : iklim organisasi, komitmen organisasional, retensi.
\end{abstract}

\begin{abstract}
Retention is an essential element of an organizational approach. Each organization should strive to retain its employees, especially employees who have important value for the organization. Maintaining the best professional talent is a very important practice for organizations such as eliminating recruitment, selection and reducing costs of their turnover, and maintaining continuity according to their area of expertise. This study aims to determine the effect of organizational climate on organizational commitment and retention of contract employees in Bappeda Litbang Bali Province by using 66 people as research respondents. Sample determination technique used in this research is using census technique. Data collection was done through interviews and questionnaires. Data analysis technique used in this research is path analysis processed using SPSS software. The results obtained in this study indicate that the organizational climate has a positive and significant relationship to organizational commitment, organizational climate has a positive and significant relationship to organizational retention and climate has a positive and significant relationship to retention.
\end{abstract}

Keyword : organizational climate, organizational commitment, retention. 


\section{PENDAHULUAN}

Badan Perencanaan Pembangunan Daerah Penelitian dan Pengembangan (Bappeda Litbang) Provinsi Bali merupakan instansi pemerintahan di Bali yang menjadi jembatan bagi Gubernur Bali dalam menjalankan visi dan misinya. Sebagaimana yang tercantum dalam Peraturan Gubernur Bali Nomor 47 Tahun 2011 tentang Rincian Tugas Pokok Badan Perencanaan Pembangunan Daerah Provinsi Bali pada Bab II disebutkan bahwa tugas badan adalah melakukan penyusunan dan pelaksanaan kebijakan di bidang perencanaan, pengendalian dan evaluasi program pembangunan. Bappeda Litbang Provinsi Bali memiliki jumlah pegawai sejumlah 174 orang termasuk seorang Kepala Badan dan Sekretarisnya, dengan rincian PNS berjumlah 103 orang, CPNS STPDN berjumlah 5 orang dan pegawai kontrak berjumlah 66 orang.

Pegawai kontrak yang dimiliki oleh Bappeda Litbang Provinsi Bali tergolong cukup banyak yang menunjukkan bahwa peran pegawai kontrak cukup penting dalam menyelesaikan pekerjaan di Bappeda Litbang Provinsi Bali. Salah satu hal yang diperhatikan dalam permasalahan organisasi adalah bagaimana mempertahankan para pegawai kontrak dan membuat pegawai kontrak melanjutkan kontraknya yang selama 1 (satu) tahun setelah masa kontraknya habis. Tymon et al. (2011) mencatat bagaimana mempertahankan bakat profesional terbaik adalah praktek sangat penting bagi organisasi seperti mengeliminasi rekrutmen, seleksi dan mengurangi biaya dari pergantian karyawan yang keluar dari organisasi, menjaga kontinuitas sesuai bidang keahlian mereka, dan mendukung budaya yang pantas dapat menjadi penghargaan. Meskipun 
dengan status sebagai pegawai kontrak tetapi keberadaan pegawai kontrak sangat membantu tenaga PNS. Jika terdapat pegawai kontrak yang keluar dari organisasi atau tidak melanjutkan kontraknya maka akan berakibat buruk pada kinerja di Bappeda Litbang Provinsi Bali.

Upaya untuk mempertahankan karyawan telah menjadi persoalan utama dalam banyak organisasi. Ketika organisasi kehilangan karyawan potensial, maka organisasi juga kehilangan kemampuan, pengalaman, dan "memori organisasi". Jika suatu organisasi tidak dapat mempertahankan karyawannya yang ditandai dengan meningkatnya employee turnover, maka hal ini merupakan suatu sinyal bahwa organisasi tersebut memiliki manajemen yang buruk dan perencanaan yang tidak matang dalam hal SDM. Salah satu faktor yang mempengaruhi retensi karyawan adalah komitmen organisasional. Komitmen organisasional mempengaruhi keputusan masa depan karyawan untuk bertahan atau meninggalkan organisasi (Simon, 2005). Mueller (2002) mencatat hubungan antara komitmen karyawan dengan keinginan karyawan untuk tetap bertahan pada organisasi, dimana rendahnya komitmen karyawan akan menimbulkan ketidakhadiran dan turnover yang disengaja.

Hubungan antara faktor tersebut mengindikasikan kebutuhan organisasi untuk meningkatkan komitmen karyawan yang akan mampu meningkatkan keinginan karyawan untuk bertahan. Organisasi yang mampu meningkatkan persepsi positif dari nilai organiasi melalui komitmen akan lebih mampu dalam menarik dan mempertahankan karyawan (Frank et al., 2004). Haque (2014) menyatakan karyawan yang mengalami kelelahan secara emosional cenderung 
mengurangi komitmen dan niat mereka untuk bertahan pada organisasi. Komitmen afektif juga dinyatakan sebagai prediktor dari niat untuk bertahan pada organisasi. Karyawan yang menyukai organisasi tempatnya bekerja menunjukkan bahwa mereka akan bekerja pada organisasi dalam jangka waktu yang lama.

Komitmen karyawan terhadap organisasi bukan merupakan suatu hal yang terjadi secara sepihak. Komitmen ikut dipengaruhi oleh iklim organisasi tempat seorang karyawan bekerja. Iklim organisasi adalah persepsi karyawan terhadap lingkungan kerja yang dapat memotivasi dan mempengaruhi niat karyawan untuk bertahan pada organisasi. Kustianto dan Iskhak (2015) serta Widiarti dan Dewi (2016) menyatakan bahwa iklim organisasi berpengaruh positif dan signifikan terhadap komitmen organisasional. Noordin et al. (2010) mengungkapkan bahwa iklim organisasi memiliki pengaruh positif pada komitmen organisasional pada karyawan di Malaysia.

Russel et al. (2013) menyatakan iklim organisasi juga dapat sebagai prediktor dari retensi karyawan. Iklim organisasi dipersepsikan sebagai peramal dari niat untuk meninggalkan organisasi (Shanker, 2014). Iklim organisasi juga berhubungan dengan kinerja, efektifitas organisasi, produktivitas, komitmen dan keinginan untuk keluar (Rahimic, 2013). Meskipun terdapat beberapa faktor lain, yaitu faktor ekonomi dan individu yang memutuskan niat untuk bertahan atau meninggalkan organisasi, namun iklim organisasi memiliki dampak utama pada penentuan niat karyawan untuk bertahan atau meninggalkan organisasi. Menurut Muceke (2012), karyawan merasa lebih puas yang akan mempengaruhi komitmen karyawan terhadap perusahaan dan apabila karyawan mempunyai pengalaman 
positif dari lingkungan kerja, karyawan tersebut akan lebih lama bertahan di organisasi tersebut.

Niat untuk keluar secara tidak langsung dipengaruhi oleh iklim organisasi melalui komitmen organisasional sebagai variabel mediasi (Nanba et al., 2012). Menurut Karsh et al. (2005) Beban kerja organisasi, rasa aman di tempat kerja, dan kualitas lingkungan kerja secara tidak langsung mempengaruhi keinginan untuk keluar melalui kepuasan kerja dan komitmen kerja karyawan. Hal ini didukung oleh wawancara yang dilakukan kepada pegawai kontrak Bappeda Litbang Provinsi Bali di mana mereka memilih untuk bertahan dan melanjutkan kontrak di Bappeda Litbang Provinsi Bali karena mereka merasa nyaman akan situasi kerja di mana adanya hubungan baik antara atasan-bawahan, antara Pegawai Negeri Sipil dengan pegawai kontrak maupun antar sesama pegawai kontrak. Mereka merasakan adanya rasa kekeluargaan pada lingkungan kerja di Bappeda Provinsi Bali yang meningkatkan komitmen karyawan yang secara tidak langsung meningkatkan retensi di organisasi. Berdasarkan hal tersebut, maka penelitian ini ingin mengetahui bagaimana pengaruh iklim organisasi terhadap komitmen organisasional dan retensi pada tenaga kontrak Bappeda Litbang Provinsi Bali.

Teori yang berkaitan dengan retensi adalah teori atribusi. Teori atribusi menjelaskan tentang proses bagaimana menentukan penyebab atau motif perilaku seseorang. Teori atribusi mengacu pada bagaimana seseorang menjelaskan penyebab perilaku orang lain atau diri sendiri, yang ditentukan apakah dari faktor internal atau eksternal yang akan berpengaruh terhadap perilaku individu. 
Penyebab perilaku dikenal sebagai dispositional attributions (penyebab internal) dan situational attributions (penyebab eksternal). Dispositional attributions (penyebab internal) mengacu pada aspek perilaku individual, sesuatu yang ada didalam diri seseorang seperti sifat pribadi, persepsi diri, kemampuan, dan motivasi. Situational attributions (penyebab eksternal) mengacu pada lingkungan yang mempengaruhi perilaku, seperti kondisi sosial, nilai sosial, dan pandangan masyarakat. Dalam teori atribusi Luo dan Baillargeon (2010) terdapat pengertian niat yang secara umum dan tidak langsung diasumsikan bahwa niat dari seseorang bertanggung jawab akan penyebab dan pedoman aksinya. Dari teori yang telah disebutkan, penelitian ini menggunakan teori atribusi yang menjelaskan sebab atau motif tenaga kontrak Bappeda Litbang Provinsi Bali untuk tetap bertahan pada organisasi atau meninggalkan organisasi.

Mathis \& Jackson (2006:126-128) menyatakan retensi karyawan merupakan upaya untuk mempertahankan karyawan di dalam organisasi.Retensi karyawan mengacu pada berbagai kebijakan dan praktik yang mengarahkan karyawan agar bertahan dalam organisasi untuk jangka waktu yang lebih lama. Retensi karyawan merupakan kemampuan yang dilakukan oleh perusahaan untuk mempertahankan karyawan yang memiliki potensi agar tetap loyal dengan perusahaan. Tngginya retensi karyawan sangat dibutuhkan dalam hal meningkatkan kinerja karyawan, jika employee retention rendah maka akan meningkatkan employee turnover sehingga mempunyai dampak negatif terhadap kinerja dan efektivitas perusahaan (Sumarni, 2011). 
Menurut Mathis dan Jackson (2006: 128), menyatakan terdapat 3 indikator di dalam retensi karyawan antara lain: 1) Karyawan bertahan karena organisasi menyediakan peluang karir yang sama bagi setiap karyawan, 2) Karyawan bertahan karena organisasi selalu memberikan penghargaan atas kinerja yang dilakukan, dan 3) Karyawan bertahan karena rekan kerja tidak pernah bertindak diskriminatif. Dua indikator dari peneliti Agboola dan Jeremiah (2011) serta Shanker (2014) sama-sama mengukur tingkat keinginan untuk tetap berada di organisasi dan niat untuk meninggalkan organisasi. Perbedaan dari dua indicator masing-masing peneliti adalah tambahan indicator yang berhubungan dengan niat karyawan untuk bertahan atau meninggalkan organisasi. Indikator dari Mathis dan Jackson (2006) menjelaskan alasan karyawan tetap bertahan pada organisasi. Penelitian ini menggunakan dua dari empat indikator dari Agboola dan Jeremiah (2011) yang sesuai dengan keadaan di Bappeda Litbang Provinsi Bali.

Menurut Hasan (2012) komitmen organisasional adalah dimensi perilaku yang digunakan dalam menilai kecendrungan pegawai untuk bertahan sebagai anggota organisasi, identifikasi dan keterlibatan seseorang yang relative kuat terhadap organisasi, serta keinginan anggota organisasi untuk tetap mempertahankan keanggotaannya dalam organisasi dan bersedia berusaha keras bagi pencapaian tujuan organisasi. Komitmen organisasional adalah suatu keadaan dimana karyawan memberikan rasa loyalitasnya dan memiliki keinginan untuk menjadi bagian dari organisasi untuk bersama-sama mencapai tujuan organiasasi. 
Iklim organisasi adalah persepsi karyawan dari lingkungan kerja yang memotivasi dan mempengaruhi kerelaan dari karyawan untuk tetap tinggal di organisasi (Shanker, 2014). Holloway (2012) mendefinisikan iklim organisasi sebagai kesatuan dari sifat terukur dari lingkungan kerja yang dipersepsikan oleh karyawan secara langsung maupun tidak langsung yang mempengaruhi dan memotivasi perilaku mereka. Iklim organisasi menjelaskan tentang kepercayaan dan nilai yang tidak nampak tetapi ada dalam tingkah laku dan tindakan karyawan (Giles, 2010). Menurut Alavi dan Jahandari (2005) iklim organisasi adalah kualitas lingkungan internal yang dialami anggota-anggotanya yang mempengaruhi sikap dan perilaku serta dapat tergambar dalam sejumlah karakteristik khusus dari suatu organisasi dan disebut sebagai kepribadian organisasi. Dapat disimpulkan dari beberapa definisi diatas bahwa iklim organisasi adalah persepsi dari karyawan mengenai kualitas lingkungan kerja internal mereka yang mempengaruhi sikap dan perilaku mereka terhadap organisasi.

Menurut Setyanto dkk. (2013) terdapat hubungan yang positif antara iklim organisasional dengan komitmen organisasi, dimana semakin baik iklim organisasi dipersepsi oleh karyawan, maka semakin kuat komitmennya terhadap organisasi. Kustianto dan Iskhak (2015) dan Widiarti dan Dewi (2016) menemukan pula hubungan yang positif antara iklim organisasi dengan komitmen organisasional dimana iklim yang kondusif akan menumbuhkan rasa komitmen karyawan yang tinggi. Noordin et al. (2010) mengungkapkan bahwa iklim 
organisasi memiliki pengaruh positif terhadap komitmen organisasional pada karyawan di industri komunikasi di Malaysia.

Iqbal (2008) menyatakan bahwa dimensi dari iklim organisasi memiliki pengaruh yang berbeda terhadap komitmen organisasional. Dimensi tantangan dan keterlibatan, kepercayaan dan keterbukaan, dukungan ide, kebebasan, dan bermain dan humor memiliki hubungan postif terhadap komitmen organisasional. Dimensi konflik memiliki hubungan negatif terhadap komitmen organisasional. Dimensi debat, waktu ide, dan pengambilan risiko menunjukan pengaruh yang tidak signifikan terhadap komitmen organisasional, tetapi secara keseluruhan memiliki hubungan positif dengan komitmen organisasional.

Berdasarkan bukti empiris tersebut maka dapat dirumuskan hipotesis sebagai berikut:

$\mathrm{H}_{1}$ : Iklim organisasi berpengaruh positif terhadap komitmen organisasional.

Coetzee (2012) dan Nugyen (2014) mengemukakan temuan bahwa komitmen organisasional berpengaruh positif dan signifikan terhadap retensi karyawan. Penelitian dari Astuti dan Mutiara (2014) dan Smith (2005) menemukan bahwa hubungan yang positif antara komitmen afektif dengan retensi, dimana besar komitmen afektif maka akan semakin tinggi retensi karyawan. Penelitian dari Shanker (2013) menunjukan bahwa dua jenis dari komitmen organisasional, yaitu komitmen afektif dan komitmen kontinu mempunyai hubungan yang signifikan terhadap retensi. Komitmen afektif mempunyai hubungan positif terhadap retensi dimana karyawan yang afektif, secara emosional berkomitmen terhadap organisasional, menunjukan keinginan 
untuk menjadi bagian dari organisasi untuk jangka waktu yang lama dengan alasan mengenali diri mereka dengan tujuan dan nilai dari organisasi, sedangkan komitmen kontinu mempunyai hubungan negatif dengan retensi. Hasil dari komitmen kontinu menunjukan karyawan yang tidak berkomitmen, tidak mempunyai keinginan untuk bekerja dengan organisasinya saat ini untuk jangka waktu yang lama, mereka menunggu kesempatan yang baik atau waktu yang tepat untuk keluar dari organisasi.

Berdasarkan bukti empiris tersebut maka dapat dirumuskan hipotesis sebagai berikut:

$\mathrm{H}_{2}$ : Komitmen organisasional berpengaruh positif terhadap retensi.

Penelitian Shanker (2014) menemukan bahwa iklim organisasi berpengaruh positif terhadap retensi. Penelitian dari Abrams et al. (2008), dan Kyndt et al. (2009) menunjukkan bahwa iklim kerja dan belajar berpengaruh secara positif terhadap retensi. Hal ini didukung oleh penelitian dari Donoghue (2010) yang menemukan bahwa iklim organisasi positif berkontribusi terhadap penurunan niat karyawan untuk meninggalkan organisasi yang berarti meningkatkan retensi karyawan. Suliman dan Obaidli (2011) meneliti hubungan antara iklim organisasi dan niat untuk meninggalkan organisasi di industri bank Islami. Penelitiannya menunjukan bahwa persepsi karyawan terhadap iklim organisasi mempengaruhi niat karyawan untuk meninggalkan organisasi dengan jalan yang negatif.

Berdasarkan bukti empiris tersebut maka dapat dirumuskan hipotesis sebagai berikut:

$\mathrm{H}_{3}$ : Iklim organisasi berpengaruh positif terhadap retensi. 


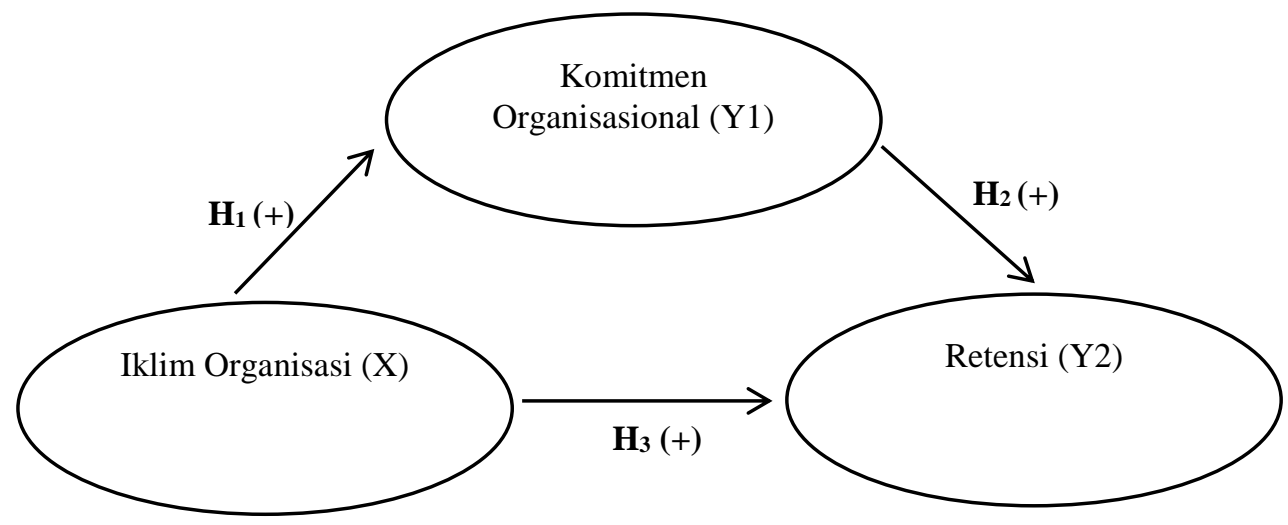

\section{Gambar 1. Kerangka Konseptual}

Sumber: Data Diolah, 2017

\section{METODE PENELITIAN}

Penelitian ini menggunakan pendekatan kuantitatif. Penelitian ini menggunakan variabel iklim organisasi, komitmen organisasional dan retensi yang akan disusun berdasarkan pendekatan kuantitatif bersifat asosiatif kausalistik. Penelitian asosiatif adalah penelitian yang bertujuan untuk mengetahui hubungan antara dua variabel atau lebih. Lokasi penelitian ini dilakukan di Badan Perencanaan Pembangunan, Penelitian dan Pengembangan (Bappeda Litbang) Provinsi Bali yang berada di Jalan Kapten Cokorda Agung Tresna, Renon. Bappeda Litbang Provinsi Bali dipilih dikarenakan peneliti ingin mengetahui alasan tenaga kontrak bertahan pada organisasi hingga ada yang memiliki masa kerja selama sembilan tahun tanpa adanya kepastian diangkat sebagai Pegawai Negeri Sipil (PNS). Subyek dari penelitian ini adalah pegawai kontrak Bappeda Litbang Provinsi Bali. Obyek penelitian ini yaitu iklim organisasi, komitmen organisasional dan retensi. Penelitian ini bertujuan untuk mengidentifikasi pengaruh iklim organiasasi terhadap komitmen organisasional dan retensi. Berdasarkan pokok permasalahan dan hipotesis yang diajukan, 
variabel-variabel dalam analisis ini dapat diidentifikasi sebagai berikut, variable eksogen yaitu iklim organisasi (X) serta variabel endogen yaitu komitmen organisasional (Y1) dan retensi (Y2).

Iklim organisasi adalah persepsi dari karyawan mengenai kualitas lingkungan kerja internal mereka yang mempengaruhi sikap dan perilaku mereka terhadap organisasi. Iklim organisasi memiliki tiga dimensi yang menjadi panduan dalam membuat indikator iklim organisasi. Dimensi yang digunakan dalam penelitian ini didasarkan oleh dimensi dari Shanker (2014), yaitu 1) Iklim Organisasi Berorientasi Hubungan 2) Iklim Organisasi Berorientasi Pengaturan Tujuan dan Kemandirian Kerja 3) Iklim Organisasi Berorientasi Kekuasaan. Komitmen organisasional memiliki tiga dimensi yang didasari oleh Meyer dan Allen (2007) yang akan dijadikan indikator dalam komitmen organisasi, yaitu: 1) Affective Commitment, 2) Contiunance Commitment, 3) Normative Commitment. Retensi karyawan adalah upaya organisasi mempertahankan karyawan untuk tetap bertahan pada organisasi. Indikator yang digunakan dalam penelitian ini menggunakan indikator dari Agboola dan Jeremiah (2011). Terdapat dua indikator dalam penelitian ini yaitu, karyawan merasa nyaman dengan pekerjaan mereka saat ini dan karyawan pernah berpikir untuk keluar dari pekerjaan ini.

Jumlah populasi di Bappeda Litbang Provinsi Bali sebanyak 66 orang. Teknik dalam penentuan sampling yang digunakan pada penelitian ini adalah dengan menggunakan teknik sensus dimana sampel diambil dari keseluruhan populasi, yaitu sejumlah 66 orang. Jenis data yang digunakan dalam penelitian ini adalah data kuantitatif dan data kualitatif, di mana data kuantitatif merupakan data 
yang berbentuk angka, yaitu djumlah karyawan. Data kualitatif dalam penelitian ini adalah jawaban dari pernyataan-pernyataan yang terdapat dalam kuesioner. Data primer dalam penelitian ini berupa observasi dan penyebaran kuesioner pada Badan Perencanaan Pembangunan Penelitian dan Pengembangan (Bappeda Litbang) Provinsi Bali. Data sekunder dikumpulkan sebagai pendukung dari data primer yaitu data yang telah ada di Badan Perencanaan Pembangunan Penelitian dan Pengembangan (Bappeda Litbang) Provinsi Bali, yaitu jumlah tenaga kerja. Penelitian ini menggunakan dua metode dalam mengumpulkan data, yaitu wawancara dan kuisioner.

Teknik analisis yang digunakan pada penelitian ini berupa teknik analisis jalur (path analysis). Sebelumnya dilakukan uji intrumen penelitian terlebih dahulu yaitu uji validitas serta uji reliabilitas, dilanjutkan dengan analisis statistik deskriptif dan analisis faktor konfirmatori. Analisis statistik deskriptif merupakan suatu statistik yang digunakan untuk menganalisa data dengan cara mendeskripsikan atau mengambarkan data mengenai karakteristik variabel penelitian yaitu, nilai rata-rata, standar deviasi, varian, nilai minimum dan nilai maksimum (Sugiyono, 2014:207). Analisis statistik deskriptif yang dipakai dalam penelitian ini adalah nilai rata-rata, nilai minimum, nilai maksimum. Teknik CFA ditujukan untuk mengestimasi measurement model, menguji unidimensionalitas dari konstruk-konstruk eksogen dan endogen. Model CFA dari masing-masing variabel penelitian, yaitu iklim organisasi (X), komitmen organisasional (Y1) retensi (Y2). Korelasi Kaiser Meyer Olkin (KMO) atau Barlett's test pada analisis faktor akan menunjukan validitas konstruk dari analisis faktor. KMO minimal 0,5 
dan nilai KMO di bawah 0,5 menunjukkan bahwa analisis faktor tidak dapat digunakan. Faktor dipertimbangkan apabila eigen value bernilai lebih besar dari satu (1) dan varian kumulatifnya minimal 60 persen untuk penelitian-penelitian ilmu sosial (Latan, 2013:46).

Menurut Utama (2016:159), analisis jalur merupakan perluasan dari analisis regresi linier berganda, untuk menaksir hubungan kausalitas antar variabel yang berjenjang berdasarkan teori. Diagram jalur mencerminkan proses kausal yang memiliki tujuan untuk membantu menganalisis dan menginterprestasikan hubungan antar variabel yang dihipotesiskan. Langkah - langkah dalam menganalisis data dengan menggunakan path analysis sebagai berikut: 1) merumuskan hipotesis dan persamaan struktural, langkah pertama analisis jalur adalah merumuskan hipotesis dan model persamaan berdasarkan teori yang ada. 2) bentuk diagram koefisien jalur, dimana terdapat tiga pengaruh yaitu pengaruh langsung, pengaruh tidak langsung serta pengaruh total. Didapatkan nilai $\mathrm{R}^{2}$, Nilai koefisien determinan $\left(\mathrm{R}^{2}\right)$ digunakan untuk mengukur besarnya kontribusi variabel iklim organisasi dan komitmen organisasional terhadap variabel retensi secara gabungan, dan juga untuk mengetahui ketepatan alat analisis data. Total keragaman data yang dijelaskan oleh model diukur dengan:

$$
\mathrm{R}_{\mathrm{m}}^{2}=1-\left(\mathrm{e}_{1}\right)^{2}\left(\mathrm{e}_{2}\right)^{2}
$$

Uji Sobel dilakukan untuk menguji peran mediasi yang diberikan oleh variabel komitmen organisasional, maka pengujian signifikan variabel mediasi dalam model dapat diperiksa dari hasil uji pengaruh tidak langsung. Dari pengujian ini dapat di teliti tingkat intervensi dari variabel mediasi apakah 
memediasi penuh (full mediation) atau memediasi sebagian (partial mediation) atau bukan mediasi.Apabila nilai kalkulasi Z lebih besar dari 1,96 (dengan tingkat kepercayaan 95 persen), maka variabel mediator dinilai secara signifikan memediasi hubungan antara variabel terkait dan variabel bebas (Preacher dan Hayes, 2004). Uji Sobel dihitung dengan rumus dibawah ini:

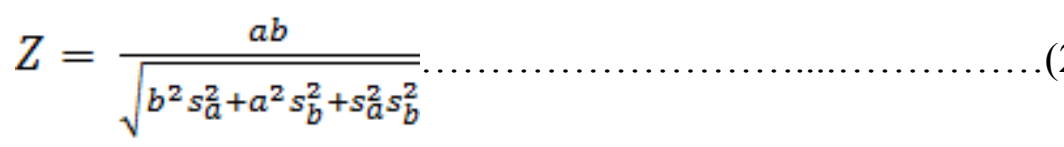

Berdasarkan pemaparan di atas mengenai persamaan struktural, maka diagram jalur dari penelitian ini sebagai berikut :

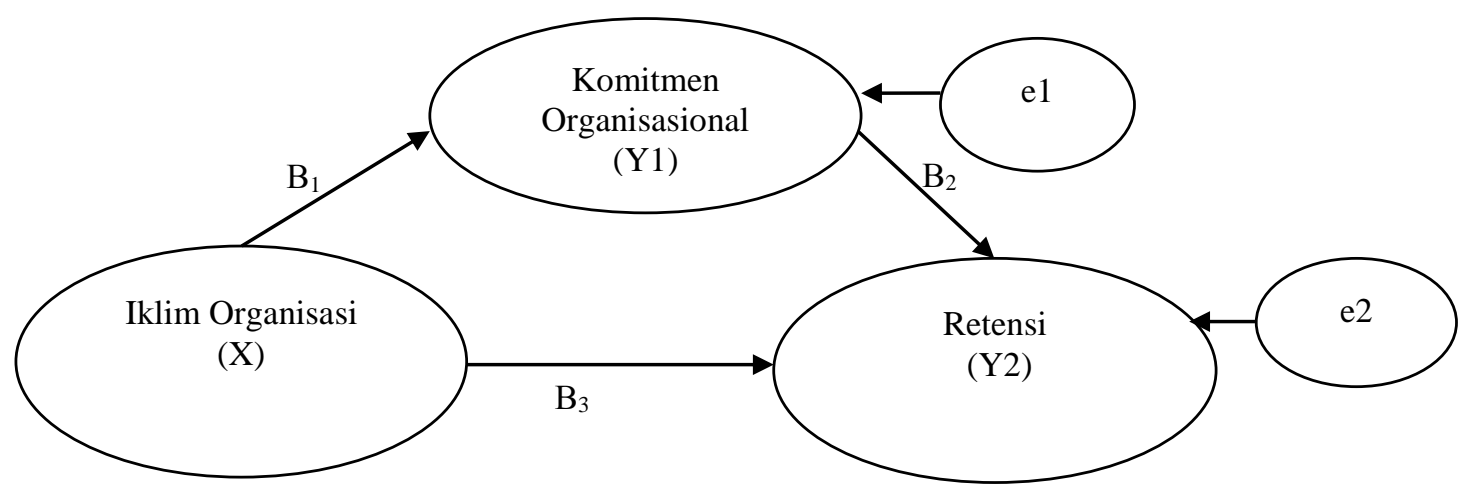

Gambar 2. Model Jalur

Sumber: Data Diolah, 2017

\section{HASIL DAN PEMBAHASAN}

Karakteristik responden berdasarkan jenis kelamin terlihat bahwa sebagian besar responden adalah perempuan (52\%). Tidak ada perbedaan yang konsisten antara pria dan wanita dalam kemampuan memecahkan masalah, ketrampilan analisis, dorongan kompetitif, motivasi, sosiabilitas, atau kemampuan belajar. Karakteristik responden berdasarkan usia jumlah tenaga kontrak terbanyak adalah tenaga kontrak berusia 21 - 25 tahun, yaitu sebanyak 29 orang atau $44 \%$ dari 
jumlah keseluruhan tenaga kontrak. Hal ini menunjukkan bahwa tenaga kontrak di Bappeda Litbang Bali memiliki usia produktif untuk bekerja. Karakteristik responden berdasarkan masa kerja tenaga kontrak terbanyak adalah selama satu (1) sampai tiga (3) tahun, yaitu sebanyak 36 orang atau 55\% dari jumlah keseluruhan tenaga kontrak. Hal ini menunjukkan bahwa selama tiga tahun terakhir jumlah tenaga kontrak terbanyak yang masuk ke Bappeda Litbang Provinsi Bali. Karakteristik responden berdasarkan tingkat pendidikan terakhir tenaga kontrak terbanyak adalah Strata 1 sejumlah 35 orang atau sebanyak 53\% dan disusul oleh tingkat pendidikan SLTA yang berjumlah 24 orang atau sebanyak $36 \%$.

Penilaian responden tentang keseluruhan variabel yang diukur dengan masing-masing indikator dan masing-masing item, Jawaban responden pada variabel iklim organisasi secara keseluruhan memiliki rata-rata skor 3,67 yang berarti iklim organisasi yang dirasakan tenaga kontrak Bappeda Litbang Provinsi Bali tergolong kondusif. Indikator yang memiliki rata-rata yang paling tinggi ditunjukan pada pernyataan "Dalam organisasi ini atasan ramah." dengan nilai rata-rata sebesar 4,05. Indikator yang memiliki rata-rata skor yang paling rendah dibandingkan dengan rata-rata skor keseluruhan ditunjukan pada pernyataan "Dalam organisasi ini kami dapat memutuskan sendiri bagaimana penyelesaian terbaik pekerjaan kami." dengan nilai rata-rata yaitu sebesar 3,21. Hal ini menunjukkan bahwa hubungan yang baik yang terjalin antara atasan-bawahan maupun sesama rekan kerja mampu meniciptakan iklim yang kondusif dalam organisasi. 
Jawaban responden pada variabel komitmen organisasional secara keseluruhan memiliki rata-rata skor 3,71 yang berarti komitmen organisasional yang dirasakan tenaga kontrak Bappeda Litbang Provinsi Bali tergolong dalam kriteria kuat. Indikator yang memiliki rata-rata yang paling tinggi ditunjukan pada pernyataan "Saya bahagia menjadi anggota dari organisasi ini." dengan nilai ratarata sebesar 3,97. Indikator yang memiliki rata-rata skor yang paling rendah dibandingkan dengan rata-rata skor keseluruhan ditunjukan pada pernyataan “Terkadang saya merasa khawatir tentang apa yang mungkin terjadi pada organisasi jika saya tidak lagi menjadi bagian organisasi." dengan nilai rata-rata yaitu sebesar 3,41. Hal ini menunjukkan bahwa perasaan bahagia dari karyawan mampu memperkuat komitmen karyawan terhadap organisasinya.

Jawaban responden pada variabel retensi secara keseluruhan memiliki ratarata skor 3,21 yang berarti retensi yang dirasakan tenaga kontrak Bappeda Litbang Provinsi Bali tergolong dalam kriteria cukup baik. Indikator yang memiliki ratarata yang paling tinggi ditunjukan pada pernyataan "Saya merasa nyaman dengan pekerjaan saya saat ini.” dengan nilai rata-rata sebesar 3,77. Indikator yang memiliki rata-rata skor yang paling rendah ditunjukan pada pernyataan "Saya pernah berpikir untuk keluar dari pekerjaan ini." dengan nilai rata-rata yaitu sebesar 2,65. Hal ini menunjukkan bahwa perasaan nyaman yang dirasakan pegawai kontrak Bappeda Litbang Provinsi Bali mampu membuat pegawai kontrak bertahan pada organisasi.

Analisis yang dihasilkan atau yang disebut sebagai measurement model digunakan untuk mengukur kuatnya struktur dari indikator-indikator variabel 
independen maupun variabel dependen. Analisis faktor konfirmatori dari penelitian ini, yakni sabagai berikut, Nilai dari KMO variabel iklim organisasi sebesar 0,622 lebih dari 0,5, dan nilai dari cumulative variance 73,125 persen > 60 persen yang berarti keseluruhan indikator variabel $\mathrm{X}$ dapat digunakan. Nilai dari KMO variabel komitmen organisasional sebesar 0,687 lebih dari 0,5, dan nilai dari cumulative variance 84,142 persen > 60 persen yang berarti keseluruhan indikator variabel Y1 dapat digunakan. Nilai dari KMO dari variabel retensi sebesar 0,500 sama dengan 0,5, dan nilai dari cumulative variance 73,872 persen >60 persen yang berarti keseluruhan indikator variabel Y2 dapat digunakan.

Tabel 1.

\section{Regresi Sub struktur 1}

\begin{tabular}{lllll}
\hline Model & Standardized Coefficients Beta & T & Sig \\
\hline Iklim Organisasi & & 0,863 & \multirow{2}{*}{13,664} & 0 \\
\hline R square & $: 0,745$ & & & \\
F.statistic & $: 186,714$ & & & \\
Constant & $: 2,599$ & & & \\
Sig. F & $: 0,000$ & & & \\
\hline
\end{tabular}

Tabel 2.

Regresi Sub struktur 2

\begin{tabular}{lcrrr}
\hline Model & Standardized Coefficients Beta & T & \multicolumn{1}{c}{ Sig } \\
\hline Iklim Organisasi & & 0,51 & 3,552 & 0,001 \\
\hline Komitmen Organisasional & & 0,336 & 2,342 & 0,022 \\
\hline R square & $: 0,669$ & & & \\
F.statistic & $: 63,581$ & & & \\
Constant & $:-3,032$ & & &
\end{tabular}

Berdasarkan perhitungan pengaruh error $\left(\mathrm{e}_{\mathrm{i}}\right)$, didapatkan hasil pengaruh error $\left(\mathrm{e}_{1}\right)$ sebesar 0,667 dan pengaruh error $\left(\mathrm{e}_{2}\right)$ sebesar 0,743. Hasil koefisien determinasi total adalah sebagai berikut : 


$$
\begin{aligned}
\mathrm{R}_{\mathrm{m}}^{2} & =1-\left(\mathrm{e}_{1}\right)^{2}\left(\mathrm{e}_{2}\right)^{2} \\
& =1-(0,667)^{2}(0,743)^{2} \\
& =1-(0,445)(0,552) \\
& =1-0,246=0,75
\end{aligned}
$$

Berdasarkan determinasi total sebesar 0,75 mempunyai arti bahwa sebesar 75 persen variasi retensi dipengaruhi oleh variasi iklim organisasi dan variasi komitmen organisasional, sedangkan sisanya sebesar 25 persen dijelaskan oleh faktor lain yang tidak dimasukkan di dalam model. Berdasarkan hasil analisis pengaruh iklim organisasi terhadap komitmen organisasional diperoleh nilai Sig. $\mathrm{t}$ sebesar 0,000 dengan nilai koefisien beta 0,863. Nilai Sig. t 0,000 $<0,05$ mengindikasikan bahwa $\mathrm{H} 0$ ditolak dan H1diterima. Hasil ini mempunyai arti bahwa iklim organisasi memiliki pengaruh positif signifikan terhadap komitmen organisasional. Berdasarkan hasil analisis pengaruh komitmen organisasional terhadap retensi diperoleh nilai Sig. t sebesar 0,022 dengan nilai koefisien beta 0,336. Nilai Sig. t $0,022<0,05$ mengindikasikan bahwa H0 ditolak dan H2 diterima. Hasil ini mempunyai arti bahwa komitmen organisasional memiliki pengaruh positif signifikan terhadap retensi. Berdasarkan hasil analisis pengaruh iklim organisasi terhadap retensi diperoleh nilai Sig. t sebesar 0,001 dengan nilai koefisien beta 0,510 . Nilai Sig. t 0,001<0,05 mengindikasikan bahwa H0 ditolak dan H3 diterima. Hasil ini mempunyai arti bahwa iklim organisasi memiliki pengaruh positif signifikan terhadap retensi. 
Berdasarkan hasil dari koefisien jalur pada hipotesis penelitian, maka dapat digambarkan hubungan kausal antar variabel iklim organisasi (X) terhadap komitmen organisasi (Y1) dan retensi (Y2) sebagai berikut.

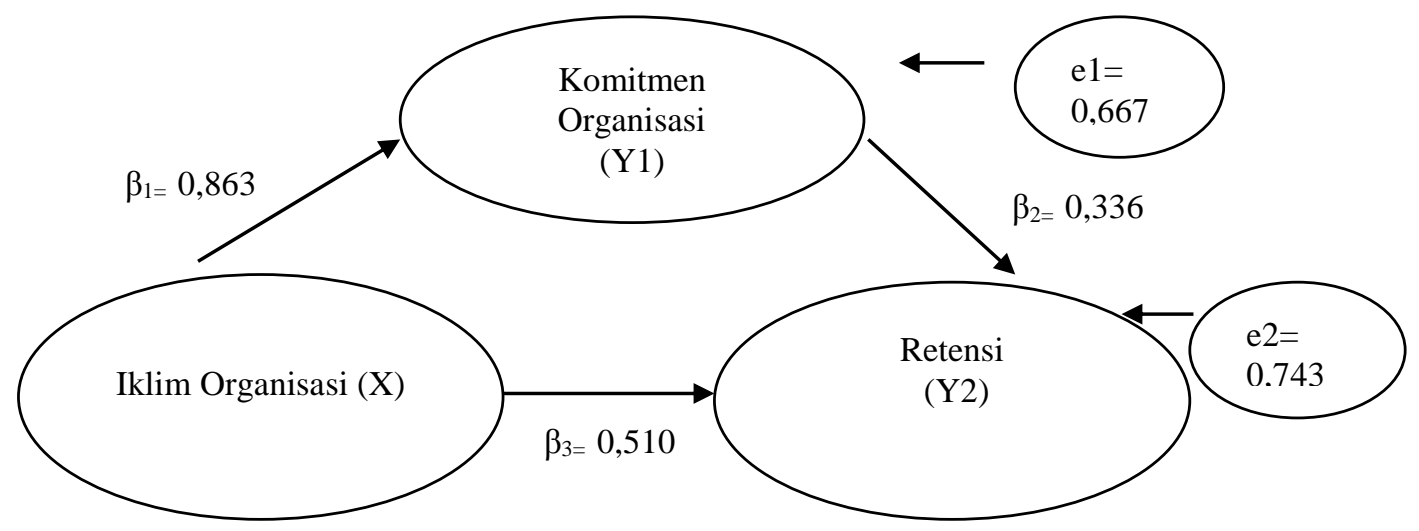

\section{Gambar 3. Model Diagram Jalur Akhir}

Sumber: Data Diolah, 2017

Pada Gambar 3. ditampilkan besaran nilai pengaruh iklim organisasi terhadap variabel komitmen organisasi dan retensi, serta besaran nilai pengaruh variabel iklim organisasi terhadap komitmen organisasional yang masing-masing nilai besaran pengaruh didapatkan dari standardized coefficient Beta dan besaran nilai setiap variabel error dari masing-masing persamaan struktural. Untuk menguji signifikansi peran secara tidak langsung digunakan rumus Sobel. Berdasarkan diagram jalur pengaruh tidak langsung tersebut, maka dapat dihitung standart error koefisien a dan b ditulis dengan $S_{a}$ dan $S_{\mathrm{b}}$ besarnya standart error tidak langsung (indirect effect) $\mathrm{S}_{\mathrm{ab}}$ dihitung dengan rumus sebagai berikut.

$$
Z=\frac{(0,863)(0,336)}{\sqrt{(0,336)^{2}(0,090)^{2}+(0,863)^{2}(0,074)^{2}+(0,090)^{2}(0,074)^{2}}} .
$$




$$
\begin{aligned}
& Z=\frac{0,290}{\sqrt{(0,113)(0,008)+(0,745)(0,005)+(0,008)(0,005)}} . \\
& Z=\frac{0,290}{\sqrt{(0,0009+0,004+0,00004)}} . \\
& Z=\frac{0,290}{\sqrt{0,005}} . \\
& Z=\frac{0,290}{0,071} . \\
& Z=4,0856
\end{aligned}
$$

Dari hasil perhitungan didapatkan perbandingan nilai z hitung sebesar 4,0856 > z tabel sebesar 1,96 maka H0 ditolak dan H1diterima. Artinya komitmen organisasional mampu mempengaruhi secara tidak langsung pengaruh iklim organisasi terhadap retensi. Besarnya pengaruh variabel iklim organisasi terhadap komitmen organisasional dan retensi secara parsial dilihat dari nilai Standardized Coeficient Beta adalah sebagai berikut.Pengaruh variabel iklim organisasi terhadap komitmen organisasional sebesar 0,863. Pengaruh variabel komitmen organisasional terhadap retensi sebesar 0,336. Pengaruh variabel iklim organisasi terhadap retensi sebesar 0,510. Iklim organisasi yang kondusif mempengaruhi tingkat komitmen karyawan terhadap organisasi yang akan meningkatkan keinginan karyawa untuk bertahan pada organisasi. Semakin kondusif iklim organisasi yang dirasakan pegawai kontrak akan memperkuat komitmen organisasional yang dirasakan karyawan yang secara tidak langsung akan meningkatkan retensi karyawan. Pengaruh total = pengaruh langsung + pengaruh tidak langsung. Pengaruh iklim organisasi terhadap retensi melalui komitmen organisasional $=0,510+0,29=0,8$. 
Berdasarkan hasil pengujian hipotesis, ditemukan bahwa iklim organisasi berpengaruh positif dan signifikan terhadap komitmen organisasional. Hal ini berarti bahwa semakin kondusif iklim organisasi yang dirasakan seperti hubungan yang baik antara atasan dengan pegawai kontrak dimana atasan memperhatikan apa yang pegawai kontrak katakan, atasan dianggap ramah oleh pegawai kontrak, serta pegawai kontrak dapat bertindak secara mandiri dalam pekerjaannya maka komitmen karyawan terhadap organisasinya akan semakin kuat.

Hal ini didukung oleh penelitian dari Clercq and Rius (2007) yang menyatakan bahwa semakin baik iklim organisasi maka akan semakin tinggi pula komitmen organisasionalnya. Hasil pengujian hipotesis ini sejalan dengan hasil penelitian yang dilakukan sebelumnya oleh Setyanto dkk (2013), Kustianto dan Iskhak (2015), Widiarti dan Dewi (2016), Noordin et al. (2010), dan Iqbal (2008)yang menyatakan bahwa iklim organisasi memiliki pengaruh positif dan signifikan terhadap komitmen organisasional.

Berdasarkan hasil penelitian terhadap pengujian hipotesis, ditemukan bahwa komitmen organisasional berpengaruh positif terhadap retensi. Hal ini berarti bahwa semakin kuat komitmen karyawan terhadap organisasinya, maka akan meningkatkan niat karyawan untuk bertahan pada organisasinya. Ketika pegawai kontrak merasa bahagia menjadi bagian dari organisasi, merasa organisasi memiliki arti penting bagi pegawai kontrak, dan memiliki sense of belonging terhadap organisasi maka keinginan pegawai kontrak untuk bertahan pada organisasi akan semakin tinggi. 
Hal ini didukung oleh penelitian dari Meyer et al. (2002) yang menyatakan bahwa komitmen organisasional membuat karyawan untuk tetap bertahan pada organisasi. Komitmen yang rendah pada organisasi mengakibatkan karyawan keluar dari organisasi (Cooper-Hakim and Viswesvaran, 2005). Hasil pengujian hipotesis ini sejalan dengan hasil penelitian yang dilakukan sebelumnya oleh Coetzee (2012), Nguyen (2014), Astuti dan Mutiara (2014), Smith (2005) dan Shanker (2013) yang menyatakan bahwa komitmen organisasional memiliki pengaruh positif dan signifikan terhadap retensi.

Berdasarkan hasil penelitian terhadap pengujian hipotesis, ditemukan bahwa iklim organisasi berpengaruh positif terhadap retensi. Hal ini berarti bahwa jika iklim organisasi kondusif maka akan meningkatkan niat karyawan untuk bertahan pada organisasi. Jika tenaga kontrak merasa diperhatikan dan dihargai oleh atasan maka keinginan karyawan untuk tetap bertahan pada organisasi akan semakin tinggi.

Hal ini sejalan dengan penelitian yang dilakukan oleh Shanker (2014) yang menyatakan bahwa dimensi dari iklim organisasi yang dirasakan oleh karyawan menggambarkan bagaimana kinerja organisasi dan bagaimana organisasi memperlakukan karyawannya yang akan mempengaruhi keputusan karyawan untuk bertahan pada organisasi. Hasil pengujian hipotesis ini sejalan dengan hasil penelitian yang dilakukan sebelumnya oleh Obaidli (2011), Donoghue (2010), Abrams et al. (2008), dan Kyndt et al. (2009) yang menyatakan bahwa iklim organisasi memiliki pengaruh positif dan signifikan terhadap retensi. 


\section{SIMPULAN DAN SARAN}

Berdasarkan hasil analisis penelitian dan hasil pembahasan pada bab sebelumnya maka simpulan dari penelitian ini adalah sebagai berikut: 1) Iklim organisasi memiliki pengaruh positif signifikan terhadap komitmen organisasional pada tenaga kontrak Bapedda Litbang Provinsi Bali. Iklim organisasi yang kondusif yang dirasakan oleh pegawai kontrak akan memperkuat komitmen karyawan terhadap Bappeda Litbang Provinsi Bali. Saat pegawai kontrak merasa diperhatikan oleh atasan mereka maka komitmen organisasional mereka akan semakin kuat. 2) Komitmen organisasional memiliki pengaruh positif signifikan terhadap retensi pada tenaga kontrak Bappeda Litbang Provinsi Bali. Kuatnya komitmen organisasional yang dimiliki oleh karyawan dalam organisasinya, maka semakin tinggi tingkat retensi karyawan. Pegawai kontrak merasa bahagia dan merasa organisasi memiliki arti penting bagi pegawai kontrak sehingga meningkatkan keinginan pegawai kontrak untuk tetap bertahan pada Bappeda Litbang Provinsi Bali.

3) Iklim organisasi memiliki pengaruh positif signifikan terhadap retensi tenaga kontrak Bappeda Libang Provinsi Bali. Iklim organisasi yang dirasakan baik oleh karyawan dapat meningkatkan retensi karyawan terhadap organisasi. Pegawai kontrak yang merasa dihargai oleh atasan dan memiliki hubungan yang baik terhadap sesama rekan kerja meningkatkan retensi karyawan pada Bappeda Litbang Provinsi Bali. 4) Iklim organisasi memiliki pengaruh tidak langsung terhadap retensi melalui komitmen organisasional pada Bappeda Litbang Provinsi Bali. Pegawai kontrak yang merasakan iklim organisasi yang kondusif yang 
dimana merasakan dihargai oleh atasan dan merasakan adanya rasa kekeluargaan di Bappeda Litbang Provinsi Bali membuat tenaga kontrak merasa bahagia menjadi bagian dari Bappeda Litbang Provinsi Bali dan memiliki sense of belonging terhadap organisasi yang akan meningkatkan keinginan pegawai kontrak untuk tetap berada di Bappeda Litbang Provinsi Bali.

Saran yang dapat diberikan, berdasarkan pada hasil analisis, pembahasan dan simpulan adalah sebagai berikut: 1) Organisasi diharapkan untuk mempertahankan dan meningkatkan iklim organiasi yang sudah dirasakan baik oleh karyawan khususnya pegawai kontrak. Atasan diharapkan mampu mempertahankan hubungan yang baik dengan bawahan bukan hanya sebagai atasan-bawahan tetapi juga sebagai rekan kerja. Dengan merasakan hubungan yang baik antara atasan maupun dengan sesama rekan kerja diharapkan pegawai kontrak Bappeda Litbang Provinsi Bali untuk tetap bertahan pada organisasinya. 2) Organisasi diharapkan mampu meningkatkan komitmen dari pegawai kontrak Bappeda Litbang Provinsi Bali. Salah satu cara meningkatkan komitmen yaitu dengan menjaga iklim organisasi yang ada. Dengan iklim organisasi dirasa kondusif oleh karyawan maka akan meningkatkan sense of belonging atau rasa memiliki terhadap organisasi dan organisasi memiliki arti penting bagi karyawan. Dengan meningkatnya rasa memiliki dan arti penting organisasi bagi karyawan maka akan meningkatkan pula keingin karyawan untuk tetap berada pada organisasi.

\section{REFERENSI}

Abbasi, S. and Hollman, K. 2000. Turnover: the real bottom line. Public Personnel Management. 29 (3), pp: 333-342. 
Abdillah, Fuad. 2012. Hubungan Kohevitas Kelompok Dengan Intensi Turnover Pada Karyawan. Journal of Social and Industrial Psychology. 1 (2), pp:5258.

Abrams, J., Castermans, S., Cools, H., Michielsen, M., Moeyaert, B., Van Meeuwen, N. And Van Nooten, L. 2008. "Leren en talent management: factoren die het behouden van (talentvolle) werknemers bei"nvloeden" ("Learning and talent management: factors which influence the retention of (talented) employees"). Unpublished Research Report. Faculty of Psychology and Educational Sciences, University of Leuven, Leuven.

Agboola, A. A. and Jeremiah, K. R. 2011. An Empirical Review of the Relationship between Job Burnout and Intention to Quit: The case of Botswana police. Botswana Journal of Business. 4 (1), pp: 48-61.

Alavi, Hamid Reza and Ramazan Jahandari. 2005. The Organizational Climate Of Kerman Shahid Bahonar University. Public Personnel Management.34 (3), pp: 247-260.

Angle, H., Perry, J. 1981. An empirical assessment of organizational commitment and organizational effectiveness. Administrative Science Quarterly. 26 (1), pp: $1-14$.

Astuti, Diah Puji dan Mutiara Sibarani Panggabean. 2014. Pengaruh kompensasi terhadap retensi karyawan melalui kepuasan kerja dan komitmen afektif pada beberapa rumah sakit di DKI Jakarta. Jurnal Manajemen dan Pemasaran Jasa. 7 (1), pp: 199-217.

Clercq, D., and Rius, I. 200). Organizational Commitment in Mexican Small and Medium-Sized Firms: The Role of Work Status, Organizational Climate, and Entrepreneurial Orientation. Journal of Small Business Management. 45(4), pp: 467-490

Coetzee, M. 2012. Retention factors in relation to organisational commitment in medical and information techonology services. SA Journal of Human Resource Management. 10 (2), pp: 1-11.

Cooper-Hakim, A. and Viswesvaran, C. 2005. The construct of work commitment: testing an integrative framework. Psychological Bulletin.131, pp: 241-59.

Crow, Mathew S., Chang-Bae Lee, Jae-Jin Joo. 2012. Organizational Justice and Organizational Commitment Among South Korean Police Officers: An Investigation of Job Satisfaction as a Mediator. Policing: An International Journal of Police Strategies \& Management. 35(2), pp: 402-423. 
Donoghue C. 2010. Nursing home staff turnover and retention: An analysis of national level data. Applied Gerontology. 29, pp: 189-206.

Fatima. 2011. Does Employee Retention Affect Organizational Competence. Industrial Engginering Letters, 1(1), pp: 24-39.

Fishbein, M and Ajzen, I. 1975. Belief, Attitude, Intention, and Behavior: An Introduction to Theory and Research. Reading, MA: Addison-Wesley.

Frank, F. D., Finnegan, R. P., \& Taylor, C. R. 2004. The race for talent: retaining and engaging workers in the 21 st century. Human Resource Planning. 27(3), pp: 12-25.

Ghosh, Piyali, Rachita Satyawadi, Jagdamba Prasad Joshi, and Mohamad Shadman. 2014. Who stays with you? Factors predicting employees' intention to stay. International Journal of Organizational Analysis. 21 (3), pp: $288-312$.

Giles, P. 2010. The Impact of Adult Degree-Completion Programs on the Organizational Climate of Christian Colleges and Universities. Doctoral Thesis at Walden University.

Goi, Mei Teh. 2014. Impact of organizational climate on intentions to leave and job satisfaction. World Journal of Management. 5 (2), pp: 14-24.

Govaerts, N., Kyndt, E., Dochy, F. and Baert, H. 2011. Influence of learning and working climate on the retention of talented employees. Journal of Workplace Learning. 23 (1), pp: 35-55.

Haque, Abdul. 2014. The influence of emotional exhaustion on inention to stay in the organization: mediating role of affective commitment. International Journal of Management and Innovation. 6(1), pp: 16-30.

Hasan, Leny. 2012. Pengaruh Kepuasan Kerja dan Disiplin terhadap Komitmen Organisasi Pegawai Dinas Perindustrian Perdagangan Perambangan dan Energi Kota Padang. Jurnal Manajemen dan Kewirausahaan. 3 (1), ISSN : 2086-5031.

Holloway, J. B. 2012. Leadership Behavior and Organizational Climate: An Empirical Study in a Non-profit Organization. Emerging Leadership Journeys. 5(1), pp: 9-35..

Iqbal, Adnan. 2008. Organizational Climate And Its Influence On Organizational Commitment. https://dialnet.unirioja.es/descarga/articulo. Diunduh 27 Mei 2017. 
Johanes, Edward dan Muchid Rofi'i. 2014. Pengaruh kompensasi dan iklim organisasi terhadap turnover intention dengan kepuasan kerja sebagai variabel intervening. Jurnal Dinamika Manajemen. 2 (2), h: 141-152.

Karsh, B., B. C. Booske and F. Sainfort. 2005. Job and organizational determinants of nursing home employee commitment, job satisfaction and intent to turnover. Ergonomics. 48(1), pp: 1260-1281.

Kustianto, Fery dan Ahmad Abidin Iskhak. 2015. Pengaruh Iklim Organisasi Terhadap Komitmen Karyawan dengan Kepuasan Kerja sebagai Variabel Intervening Pada PT Garam (Persero). e-Jurnal Ilmu Manajemen MAGISTRA. 1 (1), h: 42-55.

Kyndt, E., Dochy, F., Michielsen, M. and Moeyaert, B. 2009. Employee retention: organisational and personal perspectives. Vocations and Learning. 2 (3), pp : 195-215.

Latan, Hengky. 2013. Model Persamaan Struktural: Teori dan Implementasi AMOS 21.0. Bandung: Alfabeta.

Luo, Y., \& Baillargeon, R. 2010. Toward a mentalistic account of early psychological reasoning. Current Directions in Psychological Science. 19(5), pp: 301-307.

Mathis, Robert L. \& John H. Jackson. 2006. Human Resource Management: Manajemen Sumber Daya Manusia. Edisi ke-10. Edisi Bahasa Indonesia. Jakarta: Salemba Empat.

Meyer, J., Stanley, D., Herscovitch, L. and Topolnytsky, L. 2002. Affective, continuance, and normative commitment to the organization: a metaanalysis of antecedents, correlates, and consequences. Journal of Vocational Behavior.61, pp: 20-52.

Meyer, J.P and Allen, N.J. 2007. A three-component conceptualization of organizational commitment: Some methodological considerations. Human Resource Management Review. 1, pp: 61-98.

Mossholder, K. W., Settoon, R. P. and Henagan, S. C. 2005. A relational perspective on turnover: Examining structural, attitudinal and behavioral predictors. Academy of Management Journal. 48(4), pp: 807-818.

Muceke, Jane. 2012. Influence of Leadership Style on Academic Staff Retention in Public Universities in Kenya. International Journal of Business and Social Science. 3(21), pp: 297-302. 
Mueller, C. W., Wallace, J. E., \& Price, J. L. 2002. Employee commitment: Resolving some issues. Work and Occupations. 19, pp: 211-236.

Nanba, Mineko., Yuki Yajima and Kazue Ninomiya. 2012. Organizational climate, organizational commitment and intention to leave among hospital new nurses in japan. Okayama Prefectual University of Health and Welfare Bulletin. 19(1), pp: 1-7.

Naz, Sumara and Seema Gul. 2014. Moderating Role of Organizational Commitment between Communication Satisfaction and Turnover Intentions Among Nurses. Pakistan Journal of Psychological Research. 29 (1), pp: 39-52.

Nguyen, T. N., Mai, K. N., \& Nguyen, P. V. 2014. Factors Affecting Employees' Organizational Commitment-A Study of Banking Staff in Ho Chi Minh City, Vietnam. Journal of Advanced Management Science.2(1), pp: 7-11.

Noordin, Fauziah, Safiah Omar, Syakirarohan Sehan and Shukriah Idrus. 2010. Organizational Climate And Its Influence On Organizational Commitment. International Business \& Economic Research Journal. 9 (2), pp: 1-10.

Preacher, K. J., \& Hayes, A. F. 2004. SPSS and SAS procedures for estimating indirect effects insimple mediation models. Behavior Research Methods, Instruments, and Computers.36, pp: 717-731.

Rageb, Mohamed A, Eman Mohamed Abd-El-Salam, Ahmed El-Samadicy and Shaimaa Farid. 2013. Organizational Commitment, Job Satisfaction and Job Performance as a mediator between Role Stressors and Turnover Intentions: A Study from an Egyptian cultural perspective. International Journal of Business and Economic Development. 1 (1), pp: 34-54.

Rahimic, Zijada. 2013. Influence Of Organizational Climate on Job Satisfaction in Bosnia and Herzegovina Companies. International Business Research. 6(1) pp: 129-139.

Roodt, G and Kotze, K. 2005. Factors that affect retention of managerial and specialist staff: an exploratory study of an employee commitment model. SA Journal of Human Resource Management. 3, pp: 48-55.

Robbins, Stephen P. 2006. Perilaku Organisasi. Edisi ke-10. Jakarta : PT Indeks Kelompok Gramedia

Robbins, Stephen P dan Timothy A. Judge. 2008. Perilaku Organisasi. Edisi Dua belas. Jakarta: Salemba Empat. 
Russel, E. M., Williams, S. W., and Gleason-Gomez, C. 2010. Teachers' perceptions of administrative support and antecedents of turnover. Journal of Research in Childhood Education. 24(3) pp:195-208.

Samuel, Michael O., Crispen Chipunza. 2009. Employee retention and turnover: Using motivational variables as a panacea. African Journal of Business Management. 3 (8), pp: 410-415.

Sager, J.K, Griffeth, R.W, \& Hom, P.W. 1998. A comparison of structural models representing turnover cognitions. Journal of Vocational Behavior. 53(2), pp: 254-273.

Setyanto, Adhi, Suharnomo dan Sugiono. 2013. Analisis pengaruh kepuasan kerja dan iklim organisasi terhadap keinginan keluar (intention to quit) dengan komitmen organisasional sebagai variabel intervening. Jurnal Studi Manajemen dan Organisasi. 10 (1), h: 75-81.

Shanker, Meera. 2013. Organizational Commitment and Employees' Intention to Stay in Indian Companies : Factor Analytical Approach. Journal of Psychosocial Research. 8 (2), pp: 199-208.

Shanker, Meera. 2014.A Study on Organizational Climate in Relation to Employees' Intention to Stay. Journal of Psychosocial Research. 9 (2), pp: 389-397.

Shim, Miseung. 2009. The effect of organizational culture and climate on employee's turnover in Public Child Welfare Agencies. PhD Dissertation University at Albany, State University of New York.

Sidharta, Novita., dan Margaretha, Meily. 2011. Dampak Komitmen Organisasi dan Kepuasan Kerja Terhadap Turnover Intention: studi Empiris Pada Karyawan Bagian Operator Di Salah Satu Perusahaan Garment Di Cimahi. Jurnal Manajemen. 10 (2), h: 81-90.

Simamora, Henry. 2004. Manajemen Sumber Daya Manusia. Edisi Kedua. Yogyakarta: BP STIE YKPN.

Simon, H.A. 2005. Boundless rationality and organizational learning. Organizational Science. 2 (1), pp: 125-134.

Smith, Mc Nees. 2005. Increasing Employee Productivity, Job Satisfaction, and Organizational Commitment. Hospital and Health Services Administration. 41 (2) pp : 160-175

Sugiyono. 2014. Metode Penelitian Kuantitatif Kualitatif dan R\&D. Bandung : Alfabeta 
Sumarni, Murti. 2011. Pengaruh Employe Retention Terhadap Turnover Intention dan Kinerja Karyawan. Jurnal Akuntansi dan Manajemen. Vol 8, pp: 2047.

Toly, A.A. 2001. Analisis faktor-faktor yang mempengaruhi turnover intention pada staf kantor akuntan publik. Jurnal Akuntansi dan Keuangan. 3 (2), h: 102-125.

Tymon, W.G. Jr, Stumpf, S.A. and Smith, R.R. 2011. Manager support predicts turnover of professionals in India. Career Development International. 16(3), pp: 293-312.

Utama, M. S. 2011. Aplikasi Analisis Kuantitatif. Edisi Kelima. Diktat Kuliah Pada Fakultas Ekonomi Universitas Udayana.

Walker, J.W. 2001. Zero defections? Human Resource Planning, 24 (1), pp: 6-8.

Wirawan, Nata. 2014. Cara Mudah Memahami Statistika Ekonomi dan Bisnis. Denpasar: Keraras Emas.

Widiarti, Ni Luh Putu Dina dan A.A. Sagung Kartika Dewi. 2016. Pengaruh Iklim Organisasi dan Kepuasan Kerja Terhadap Komitmen Organisasional pada Dinas Pendapatan Provinsi Bali. E-Jurnal Manajemen Unud. 5 (10), h: 6342-6372.

www.bappeda.baliprov.go.id/id/Gambaran-Umum-Bappeda. Diakses tanggal

Februari 2017 